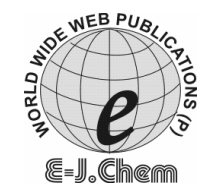

http://www.e-journals.net
CODEN ECJHAO

E-Journal of Chemistry

Vol. 3, No.2, pp 65-67, May 2006

\title{
A New, Eco-friendly Method for Iodination of Activated Arenes
}

\author{
R. SATHIYAPRIYA and R. JOEL KARUNAKARAN* \\ Department of Chemistry \\ Madras Christian College, Tambaram, \\ Chennai - 600 059, Tamilnadu, India. \\ E-mail:joelkarunakaran2005@yahoo.com
}

Received 16 December 2005; Accepted 14 April 2006

\begin{abstract}
An effective, eco-friendly method for iodination of arenes is presented. The reaction of activated aromatics with a mixture of sodium iodate and sodium sulphite in the presence of hydrochloric acid gives mono iodoarenes in high yields.
\end{abstract}

Key words: Aromatic iodination, activated arenes, sodium iodate, sodium sulphite

\section{Introduction}

Iodo aromatics are useful materials or intermediates for the production of specialty chemicals like medical drugs, agricultural chemicals, photosensitive materials, dyestuffs etc. They are also useful for the preparation of organometallic reagents and in metal catalysed coupling reactions which are applied for the preparation of complex molecules ${ }^{1}$. Apart form the applications; preparation of iodo organic is also an interesting one due to the least reactive nature of iodine among the halogen. Hence, iodination simply by molecular iodine is not possible; with most of the aromatic substrates, a powerful iodinating species more than iodine is required. This is usually achieved by adding an oxidant like $\mathrm{CrO}_{3}{ }^{2} \mathrm{NO}_{2}{ }^{3}$ $\mathrm{KMnO}_{4}{ }^{4}{ }^{4}$ Silversulphate, ${ }^{5}$ etc. with diiodine or by using an iodonium donating reagents like $\mathrm{N}$-iodosuccinidimide, ${ }^{6,7}$ iodine mononochloride, ${ }^{8} \quad \mathrm{NaI} /$ Conc. $\mathrm{H}_{2} \mathrm{SO}_{4},{ }^{9}$ etc. Most of these methods require toxic reagents and /or severe reaction conditions and by leaving hazardous 
waste make environmental problems. In this communication, we wish to report an environmental friendly procedure for the iodination of activated aromatic compounds using the reagent: $\mathrm{NaIO}_{3} / \mathrm{Na}_{2} \mathrm{SO}_{3} / \mathrm{HCl}$.

\section{Experimental}

Purity of the iodoproduct was checked by TLC technique on silica gel-G coated aluminium plate, using hexane as eluent. The chromatogram was developed under a mixture of $1 \%$ vaniline and 5\% ethanolic sulfuric acid as reagent. Melting points were obtained on a Thomas-Hoover apparatus in open capillary tubes and are uncorrected. Mass spectra were recorded on GC-MASS SPEC FINNIGAN MAT 8230MS Spectrophotometer. ${ }^{1} \mathrm{H}$ NMR and 13C NMR spectra were acquired on JEOL 270 and $400 \mathrm{MHz}$ and Varian Gemini $300 \mathrm{MHz}$ Spectrophotometers.

\section{Iodination procedur}

A solution of 2-naphthol $(1.44 \mathrm{~g}, 10 \mathrm{mmol})$, Sodium iodate $(1.98 \mathrm{~g}, 10 \mathrm{mmol})$ and sodium sulphite $(2.52 \mathrm{~g}, 20 \mathrm{mmol})$ was prepared in methanol $(5 \mathrm{~mL})$ and $40 \mathrm{~mL}$ water. This mixture was treated at room temperature with $10 \mathrm{mmol}$ of hydrochloric acid over $2 \mathrm{~h}$. After completion of reaction (TLC monitoring), the reaction mixture was extracted with diethyl ether $(4 \times 10 \mathrm{~mL})$. The ether extract was washed with dilute sodium thiosulphate $(5 \%)$, water and dried over anhydrous $\mathrm{Na}_{2} \mathrm{SO}_{4}$. Removal of solvent gave a residue which was purified through a short column packed with silica gel using hexane as eluent to afford 1-iodo-2naphthol $(2.51 \mathrm{~g}, 93 \%)$, mp. $91^{0} \mathrm{C}$ (lit. $\left.92^{\circ} \mathrm{C}\right)$. MS m/e = 264. ${ }^{1} \mathrm{H}$ NMR $\left(\mathrm{CDCl}_{3}\right): \delta 7.94(\mathrm{~d}, 1$ $\mathrm{H}, \mathrm{J}=9 \mathrm{~Hz}, 8-\mathrm{H}$ ), 7.66 (overlapping doublets, $2 \mathrm{H}, 4-\mathrm{H}$ and 5-H), 7.51 (t, I H, J = $8 \mathrm{~Hz}, 7-$ $\mathrm{H}), 7.32(\mathrm{t}, 1 \mathrm{H}, \mathrm{J}=8 \mathrm{~Hz}, 6-\mathrm{H}), 7.27(\mathrm{~d}, 1 \mathrm{H}, \mathrm{J}=8 \mathrm{~Hz}, 3-\mathrm{H}) ;{ }^{13} \mathrm{C} \mathrm{NMR}\left(\mathrm{CDCl}_{3}\right): \delta 155.2$, 135.6, 132.3, 130.5, 130.4, 126.8, 126.7, 125.4, 117.7, 86.6.

\section{Results and Discussion}

Initially, the test reaction was carried out on 2-naphthol with sodium iodate and sodium sulphite in the presence of hydrochloric acid in aqueous methanol according to the stoichiometry.(Eq.1)

$$
\mathrm{Ar}-\mathrm{H}+\mathrm{IO}_{3}^{-}+2 \mathrm{SO}_{3}^{-}+\mathrm{H}^{+}+\underset{15-25 \mathrm{~h} \text { room temp }}{\stackrel{\mathrm{H}_{2} \mathrm{O} / \mathrm{MeOH}}{\longrightarrow}} \mathrm{Ar}-\mathrm{I}+\mathrm{H}_{2} \mathrm{O}+2 \mathrm{SO}_{4}{ }^{2-}
$$

Careful product analysis (TLC, elemental analysis, mass, ${ }^{1} \mathrm{H}$ NMR and ${ }^{13} \mathrm{C}$ NMR) confirmed the formation of 1-iodo-2-naphthol with excellent yield.

To generalize this iodination reaction of arenes, different activated aromatic substrates were chosen and the reactions were carried out under similar reaction conditions ( Table 1). As expected, all the substrates undergo iodination reactions and delivered mono iodo product in good yields.

In this iodinating system, the possible iodination reactions of aromatic compounds are shown in scheme 1. When sodium iodate is treated with sodium sulphite in the presence of hydrochloric acid, iodide anion is liberated. The iodide anion thus formed undergoes oxidation reaction with iodate and furnishes more reactive electrophilic iodonium ion which can affect aromatic iodination. 


$$
\begin{aligned}
2 \mathrm{IO}_{3}^{-}+6 \mathrm{SO}_{3}^{-} \longrightarrow 2 \mathrm{I}^{-}+6{\mathrm{SO}_{4}}^{-} \\
3 \mathrm{Ar}-\mathrm{H}+2 \mathrm{I}^{-}+\mathrm{IO}_{3}^{-}+3 \mathrm{H}^{+} \longrightarrow 3 \mathrm{Ar}-\mathrm{I}+3 \mathrm{H}_{2} \mathrm{O}
\end{aligned}
$$

Scheme 1.

\begin{tabular}{|c|c|c|c|}
\hline Substrate & $\begin{array}{c}\text { Time } \\
\mathrm{h}\end{array}$ & Product & Yield $_{\%}^{c}$ \\
\hline Aniline & 2.0 & Iodoaniline $^{\mathrm{a}}$ & 93 \\
\hline 2-Aminonaphthalene & 2.0 & 2-Amino-3-iodonaphthalene & 91 \\
\hline 4-Nitroaniline & 2.5 & 2-iodo 4-nitroaniline & 89 \\
\hline 4-Chloroaniline & 2.5 & 4-chloro 2-iodoaniline & 90 \\
\hline Anisole & 2.0 & 1-iodo 4-methoxy benzene & 84 \\
\hline Phenol & 1.5 & Iodophenol $^{\mathrm{b}}$ & 96 \\
\hline 4-Chlorophenol & 2.0 & 4-chloro 2-iodophenol & 88 \\
\hline 2-Nitrophenol & 2.15 & 4-iodo 2-nitrophenol & 86 \\
\hline Salicylic acid & 2.5 & 5-iodosalycylic acid & 79 \\
\hline 2-Naphthol & 2.0 & 1-iodo 2-naphthol & 93 \\
\hline
\end{tabular}

Table 1. Iodination of aromatics with $\mathrm{NaIO}_{3} / \mathrm{Na}_{2} \mathrm{SO}_{3} / \mathrm{HCl}$

\section{Conclusion}

In conclusion, convenient and versatile procedure for iodination of activated arenes has been reported. In this method, neither harmful reagents are used nor toxic residue are left after completion of the reaction. Thus, this iodination reactions are indeed, environmentally benign. In each case, mono iodination was identified with high yields.

\section{References}

1 Diederich $\mathrm{F}$ and Stang $\mathrm{P}$ J, Metal catalysed Cross -Coupling Reactions; Ed; Wiley-VCH: Weinheim, Germany, 1998.

2 Lulinski P and Skulski L Bull. Chem. Soc. Jpn. 1997, 70, 1665.

3 Noda Y and Kashima M Tetrahedron Lett. 1997, 38, 6225.

4 Lulinski P and Skulski L Bull. Chem. Soc. Jpn. 1999, 72, 115.

5 Sy W -W Tetrahedron Lett. 1993, 34, 6223.

6 Carreno M C, Ruano J L T, Sanz G, Toledo M A and Urbano A Tetrahedron Lett. 1996, 37, 4081.

7 Anne-Sophie Castanet, Francoise Colobert and Pierre-Emmanauel Broutin Tetrahedron Lett. 2002, 43, 5047.

8 Hubig S M, Jung W and Kochi J K J. Org. Chem. 1994, 59, 6233.

9 Pasha M A and Yi Yi Myint Synth. Commun. 2004, 34(15), 2829. 


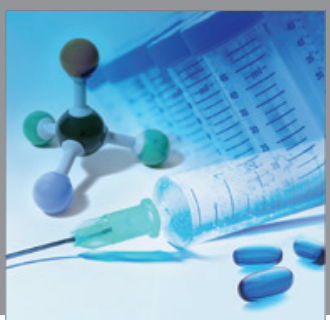

International Journal of

Medicinal Chemistry

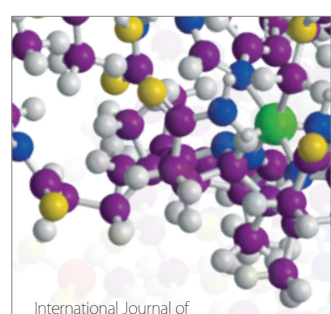

Carbohydrate Chemistry

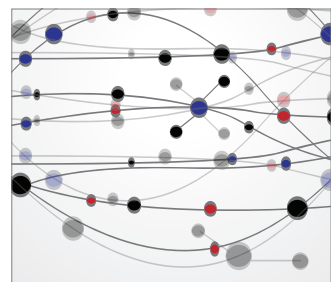

The Scientific World Journal
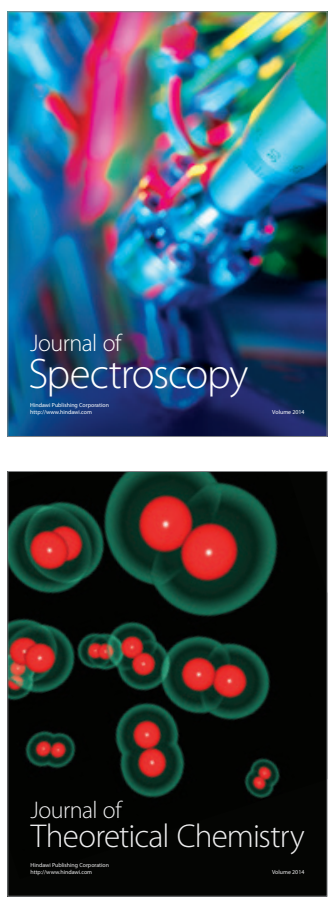
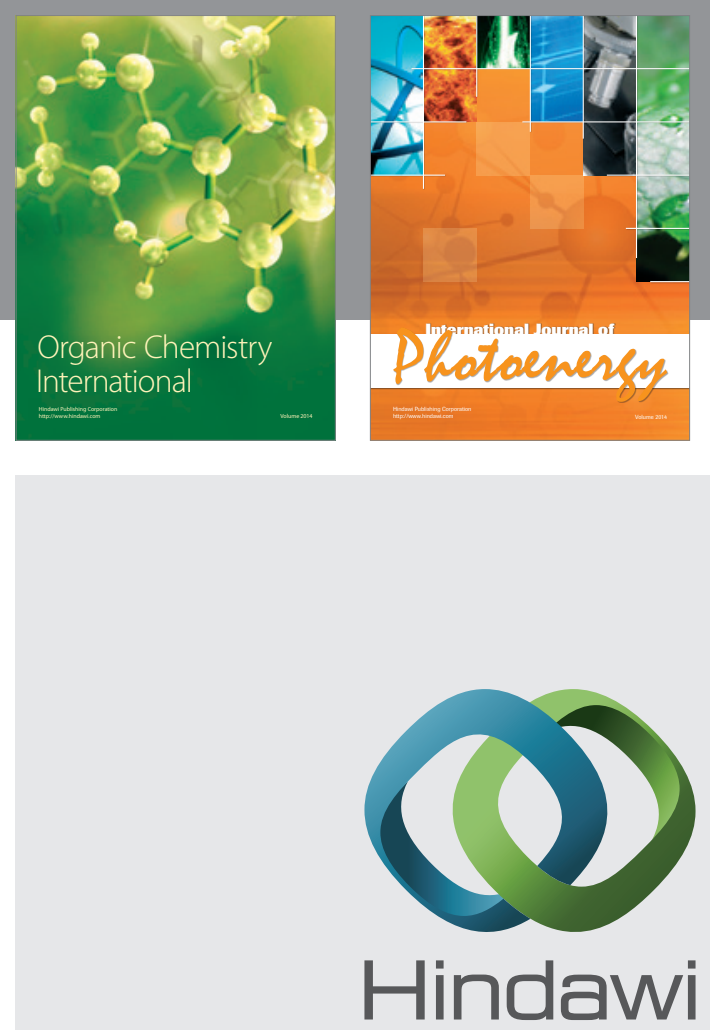

Submit your manuscripts at

http://www.hindawi.com
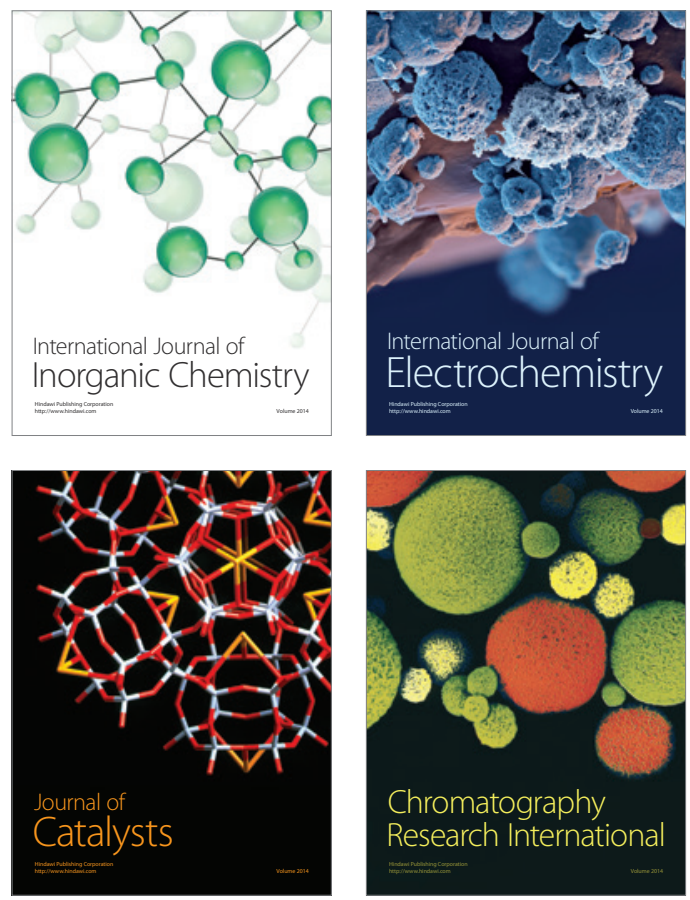
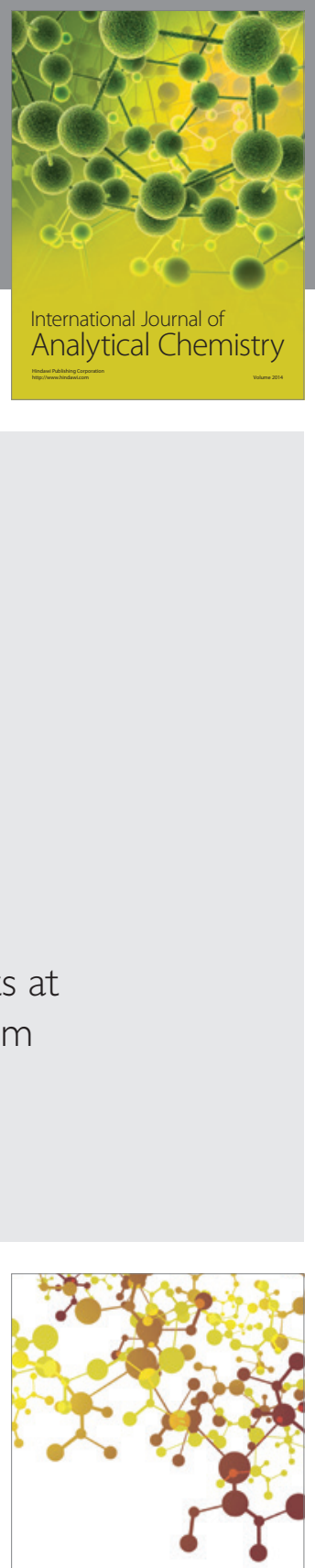

Journal of

Applied Chemistry
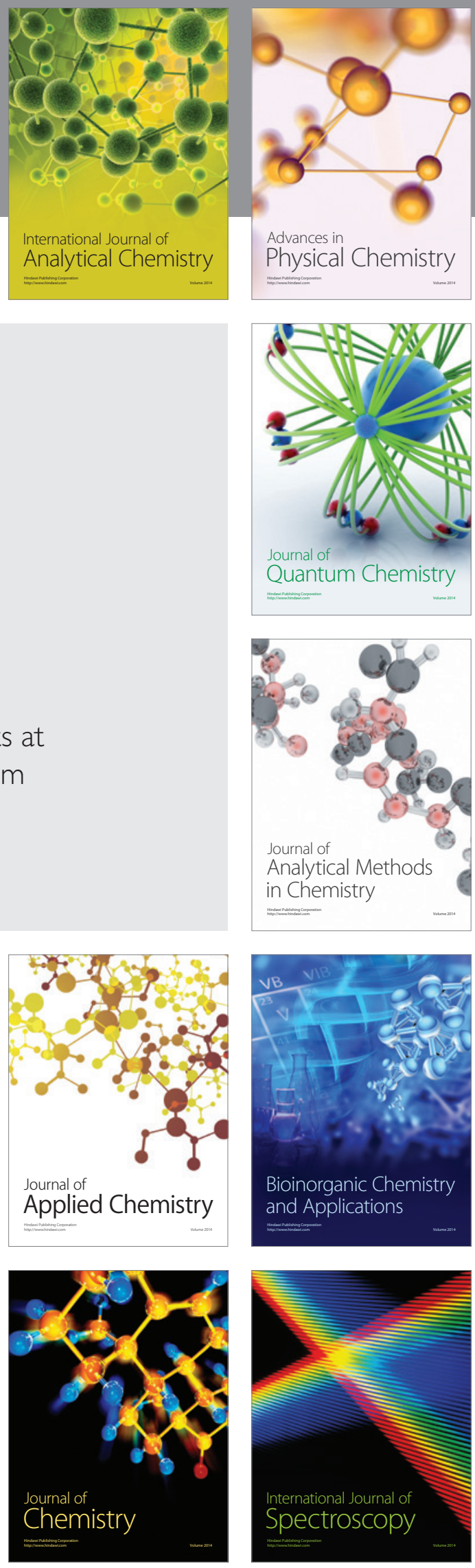